Journal of Teacher Education for Sustainability, vol. 13, no. 2, pp. 44-58, 2011

\title{
FURTHER EDUCATION FOR TRAINERS AND TEACHERS - FINDINGS OF THE PROJECT "EUROCRAFTS 21 - MAKING HANDICRAFT SUSTAINABLE”
}

\author{
Anna Bliesner \\ Wuppertal Institute for Climate, Environment, Energy, Germany \\ Christopher Manstein \\ Factor 10 Institute, Austria \\ Holger Rohn \\ Trifolium-Beratungsgesellschaft mbH, Germany
}

\begin{abstract}
The purpose of the paper is to share the findings of a European innovation transfer project (2008-2010) for strengthening sustainability in European handicraft with the aim of transferring a German qualification and consulting concept. The focus of the paper is a trainthe-trainer design, which was developed, tested and evaluated with regard to the specific qualification needs and the existing qualification concepts of five European countries. The paper provides content, didactic approach and methods of the train-the-trainer design and the key results of the related analysis of research data. Furthermore, the train-the-trainer design is embedded within the project approach, the methodology of realising an innovation transfer and the associated project products. The results of the train-the-trainer design evaluation are reflected upon with regard to starting points of a European qualification concept for sustainability in handicraft.
\end{abstract}

Key words: sustainable development, innovation transfer, further education, handicraft enterprises, qualification and consulting concept, train-the-trainer

\section{Introduction}

It is widely evidenced that small and medium-sized enterprises (SMEs) with a firmly established and practiced corporate strategy of sustainable management benefit from competitive advantage (European Commission, 2007; Mandl \& Dorr, 2007). The internal capability of enterprises to initiate innovations and to successfully implement them in the long term largely depends - besides organisational and technical conditions - upon the people who 
work in the respective enterprise (Henning, Oertel, \& Isenhardt, 2003; Anlauft, 2007) and their qualifications and competencies (Stadelmann, 2004; Hartmann, Brentel, \& Rohn, 2006).

This is correlated with the need for qualified trainers, teachers and consultants to enable people in SMEs to face the challenge of sustainable management. Most SMEs in Europe are located in the craft sector. Here appropriate qualification and consulting possibilities in the context of sustainable management are still missing. Therefore, the European craft sector is a significant target group for trainers and teachers with the aim of enhancing sustainable global business. In order to meet this challenge, they themselves need to be trained. For this purpose, a train-the-trainer design related to a qualification and consulting concept (QCC) developed within the European innovation transfer project "EuroCrafts 21 making handicraft sustainable” (2008-2010, EU Life Long Learning Program) is presented below. The project aims to contribute to a more sustainable European Craft sector as this is a main challenge of the 21st century ("EuroCrafts 21").

In the project, ten partner organisations from six EU countries (Austria, Finland, Germany, Hungary, Slovakia and Spain) realised the transfer and further development of an innovative German QCC (Westdeutscher Handwerkskammertag, 2007) in the context of sustainable development for European craftsmen. The target groups for the development of competencies were educational staff at further vocational education and training institutes, owners of enterprises and business executives as well as consultants and multipliers. The project partners, in addition to some 70 European trainers and 18 pilot enterprises, attended the project work (Leinonen \& Ryynänen, 2010). As a central instrument for realising the innovation transfer, a train-the-trainer design was developed, piloted and evaluated.

Regarding the contents, the existing German QCC was expanded by the development of six new modules (Figure 1). The main result of the project EuroCrafts 21 is an extensive internet tool with 16 different qualification modules for sustainable development in the craft sector, which is also available as a CD-ROM/DVD (Manstein \& Rohn, 2010). All results and products of the project as well as the internet tool are described on the project's homepage (www.eurocrafts21.eu).

In terms of education policy and economic strategy, the project was well placed among political efforts to achieve a more sustainable mode of production. The project is embedded into the Lisbon and EU Sustainability Strategy (see also "Europe 2020") as well as the UN Decade of Education for Sustainable Development and is supposed to contribute essentially to their implementation.

Hereafter, the focus falls on the function, concept and evaluation of the developed train-the-trainer design in connection to the QCC. For this purpose, the QCC used and developed in the project is first introduced explaining the train-the-trainer design as found in the sections for content and methodology. The project context illustrates the foundations of the methodological procedure developed for the concept design of train-the-trainer and further outlines its content and method. Next, methodology and results of the evaluation of the train-the-trainer design are presented. The succeeding discussion places the train-the-trainer design in a wider context of a European qualification and consulting concept (EQCC), for which first starting points were identified in the EuroCrafts 21 project. The closing of the paper provides a short conclusion. 


\section{Framework conditions: The qualification and consulting concept}

\section{Target group needs}

The QCC is designed to integrate the guiding principle of sustainability into existing business processes in SMEs. It considers the context of SMEs in the craft sector, in particular, that they are driven by day to day business and can afford little additional resources (Kuhndt, von Geibler, \& Villar, 2003) but still wish to improve their competitive position by incorporating sustainability. The concept considers existing business processes that take place in SMEs and frames these processes within the guiding principle of sustainability. Instead of providing additional measure, this approach is based on existing structures and operations and thereby offers a framework in which the implementation of steps towards more sustainable business processes can be categorised and, thus, implemented more easily. Sustainability as an integrated element can be identified within the content of the QCC and its approach in consulting, assessment and qualification. The approach of the QCC brings together advisory and qualifying aspects that consider the particularity of SMEs in the craft sector: scarce time, financial and human resources, limited possibilities for implementing training for sustainability by own initiative (European Association of Craft, Small and Medium-sized Enterprises, 2010). It recognises that enterprise owners and business executives need a flexible approach and often a certain degree of support.

\section{Structure}

The QCC is a modular concept that is composed of basic and special modules freely chosen, consisting of content components and learning materials (Figure 1).

The basic modules (marked with B) contain the core aspects necessary for the qualification in sustainable business in the crafts sector. They include an introduction to the topic of sustainable development (B1) and a self-assessment tool for enterprises (B2). Module B1 and B2 can be used independently, but module B1 creates the foundations for the selfassessment concerning sustainability issues. The self-assessment tool is a questionnairebased instrument, which helps enterprises and organisations to find out about futurecompliance of their operations. The self assessment serves to review the current situation of businesses in the crafts sector in order to establish their available strengths and activate accessible potentials as well as initiate improvement by introducing a first action plan in these businesses. The aim of the approach is to point out specific needs for information, training and development in crafts businesses and base this on strengths and potentials that they have recognised themselves by conducting the self assessment in their companies. The special modules (marked with S) serve to address specific qualification needs that are recognised by self-assessment. 


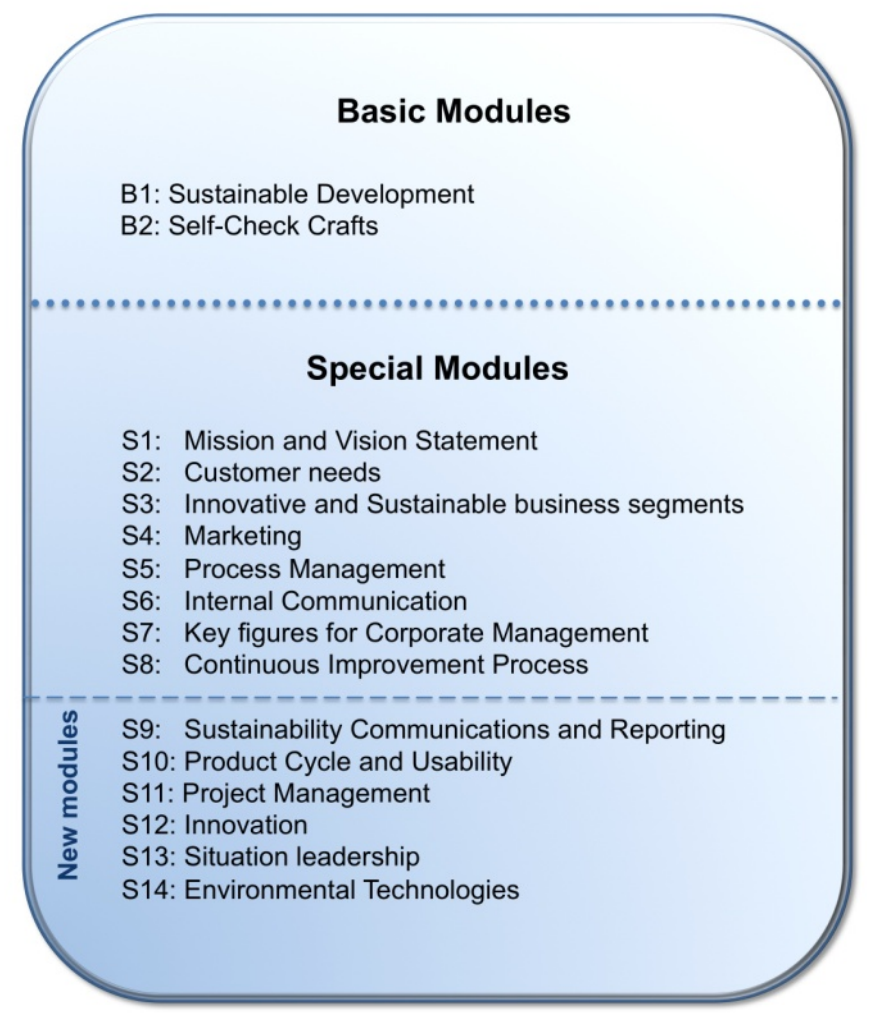

Figure 1. Modules of the qualification and consulting concept (own source)

As part of the innovation transfer, the German QCC was extended, adapted and customised so that QCC now spans 16 modules (Figure 1).

All QCC modules follow the same structure. After an introductory module description the content is presented in form of three to five content components, which introduce the topic. References to further literature, useful media and links are given. Each module includes a number of work-sheets from which a selection can be taken. The work-sheets are designed so that they can be used as a direct master copy for the learners - they include instructions directed specifically to them. In addition the work-sheets include a section with hints for the trainers: how to conduct the qualification sessions and what is the necessary time frame for the implementation of the relevant material. Competence and knowledge acquisition through direct reference to the individual scope of action from the participants is supported through the different modules of the QCC. The work-sheets aim at different levels of competence development: reflection, cooperation and communication, participation, dealing with information as well as professional expertise. 


\section{Didactic approach/enabling method}

The work-sheets pay special attention to applying learning and action formats whose didactic approach aims at learning according to an enabling approach (Holzkamp, 1996; Arnold, 1999; Siebert, 2005). This didactical approach is based on the assumption that learning can be stimulated and/or supported as construction of reality by certain methods. The prioritising of specific methods can be traced back to didactical principles (for instance, BundLänder-Kommission, 1998), which allow implication for teaching-learning-activities. In the design of the materials, the didactical principles of the subject and behaviour orientation as well as the problem orientation and reflection were taken into account (Schüßler, 2003; Pätzold \& Wortmann, 2006). On the micro-didactical level, construction methods are preferred to instruction methods in the QCC (Siebert, 2006). The choice of methods for the work-sheets is based on the following criteria:

- Methods should focus on different learning forms/forms of action: listening, reading, writing, presenting something, discussing, reflecting, and finding arguments.

- Methods should be on different levels of difficulty (easy: brain storming vs. complex: role-play).

- $\quad$ The method-mix should consist of creative methods (painting a picture), instrument-related methods (making a SWOT analysis: strengths, weaknesses, opportunities, threats), communicative methods ("role play") and reflective methods (“time travel”).

The methods should enable the learners to mentally discover the subject of the lesson themselves (Stengel, Liedtke, Baedeker, \& Welfens, 2008; Welfens, Liedtke, \& Schaefer, 2008).

\section{Extendibility and areas for application}

The concept can be enlarged on every level by adding a whole new module, a single content component (new subtheme) or/and a new work-sheet. The modules as well as the content components and work-sheets are independently usable, so no fixed order has to be followed. Although the modules have been designed for the target group of managers in the crafts sector, the provided work-sheets, methods and media can be useful and educational to a wide range of users: from the highly advanced to those with no previous knowledge. This aims at a broad and flexible usability and applicability of the QCC in the European crafts sector.

\section{Medial processing}

The developed QCC and other products were processed for the target groups as multilingual online tool (www.eurocrafts21.eu; Manstein \& Rohn, 2010). This tool is free of charge. The main language of the EuroCrafts 21 tool is English, but several materials are also available in other native languages (German, Finish, Spanish, Hungarian, Slovakian). 
The modules and work-sheets are offered in a way that aims at intuitive navigation. Therefore, basic modules and special modules are separated and modules, content components and work-sheets are numbered (module B1, content component B1-A to B1-n, work-sheet B1-A1 to B1-An). To allow adaption and application tailored to specific needs, documents, such as work-sheets, are in word format. This way users are able to make changes within materials. The tool is also designed in a flexible way, which allows a supplement of further languages as well as further content.

\section{Approach and conditions of development: The train-the-trainer design}

\section{Context}

The qualification was designed as a workshop format. The aim of the train-the-trainer workshops was to offer a theoretical and practical qualification for trainers by going through a train-the-trainer workshop first and then putting their new knowledge into practice by leading a pilot-testing with at least one craft enterprise (Figure 3). During the 1.5 day workshops, content and structure of the QCC was explained and experienced by trainers, teachers, consultants and multipliers of the craft sector. During the workshops, the participants gained competencies concerning the use of the QCC as well as professional and methodological knowledge. The target groups of the workshops were teachers and trainers of vocational education in the craft sector as well as consultants in crafts sector and multipliers, who wanted to qualify enterprises by enabling them to make use of sustainability potentials in their every-day-business.

\section{Competencies}

The train-the-trainer workshops were designed in content and method to realise a broad competency development of the trainers. On the one hand, the workshops aimed for the professional qualification of trainers to participate in the training processes specific to their specialist field's (for instance, technology) know-how. On the other hand, the promotion of skills and knowledge beyond their field was important in order to pass on the content of the QCC adequately. Such competencies mainly represent the methodological and social skills of participating actively and constructively in sustainable management and skills of independent initiation, which empower others to participate in these processes.

\section{Structure and basic conditions}

The train-the-trainer workshops included informational input-parts and active work-parts. Using concrete learning material of the QCC modules, the participants, on the one hand, gained experience of the existing material. On the other hand, they became more familiar 
with the structure of the QCC. All workshops were based on the same basic structure and common targets.

The train-the-trainer workshops were planned for up to a maximum of 15-20 participants. The language of the workshop was English. An extensive preparation beforehand was not prepared, but short descriptions in English of the overall concept were delivered.

The basic structure of the train-the-trainer workshop was arranged to be flexible in a certain frame. It could be enlarged or downsized in the different phases of the structure. If the participants of the workshop had previous extensive knowledge about sustainability, work phase No. 2 was downsized, for instance. The adaptation of the basic structure depended on the needs of the target group and the working conditions.

The content of the train-the-trainer was described on the level of learning outcomes in order to ensure first steps in the extendibility to European Educational Policy and in an effort towards European comparability of competencies.

\section{The train-the-trainer design in the context of the project approach for realising innovation transfer}

The train-the-trainer design is embedded in the concept of realising innovation transfer. In order to raise the QCC to the European level, numerous analyses were conducted.

To ensure the extendibility and suitability of the QCC in terms of content and didactics, the status quo of the existing qualification and consultation concepts with the focus of sustainability of SMEs in the craft sector was surveyed in a first step. Upon identification of these concepts, they were evaluated regarding their strength and weaknesses. A stakeholder analysis of the participating partner organisations in the project and an assessment of the stakeholders' qualification needs highlighted the target groups for the QCC and the needs to be addressed. Based on these analyses, the QCC was further reflected in terms of the country specific needs, however maintaining the essential features of the concept like the module structure and the didactic approach. The changes were thus limited to adaptations in content. The train-the-trainer design was created according to stakeholders' needs so that it could address the differing levels of previous knowledge on sustainability issues with a good degree of flexibility in the procedure. The application of the work-sheets was likewise adapted to suit the aspiration level of content and method. Moreover, the selection of worksheets in the train-the-trainer workshops enabled a country specific content adaption.

Building on the mentioned analyses, the project partners developed country specific implementation concepts for the QCC. In this context, the pilot concept for the innovation transfer was generated and implemented (Figure 2), for which the train-the-trainer design represented the starting point.

Upon certified completion of the train-the-trainer workshop, trainers were involved in the pilot-testing concept. For the pilot-testing of the QCC in the partner countries participating in the project EuroCrafts 21, 18 enterprises from five European countries were involved. Subject of the pilot testing with the enterprises were the basic modules (B1 \& B2) and the adaption and implementation of existing special modules of the QCC, followed by the development and pilot testing of new country specific special modules. During this pilot 
testing process, the involved national trainers experienced a deepening qualification by guiding the enterprises though the process and using the QCC in real working life.

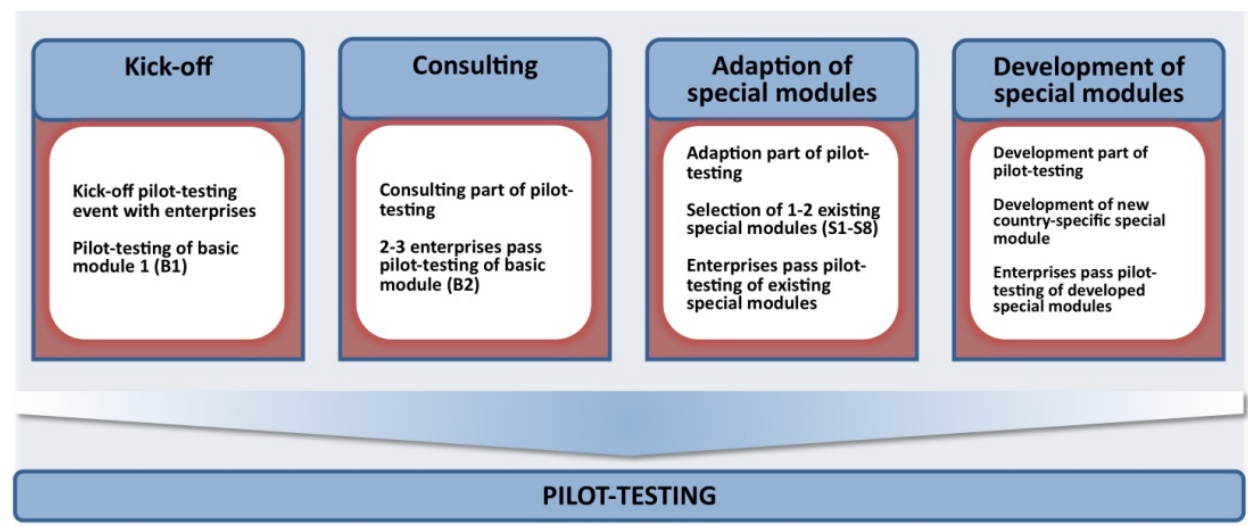

Figure 2. Pilot-testing process of EuroCrafts 21 (own source)

\section{Evaluation}

\section{Evaluation of the train-the-trainer design}

Focussing on the trainers' experiences with the QCC, the following was remarked about the design and the results of the evaluation concerning the train-the-trainer workshops.

After completing the train-the-trainer workshop, the trainers took part in a written evaluation. Because of the explorative character of the evaluation, the amount of participants was limited and a more qualitative instead of a representative approach was followed.

The participants were asked to scale their opinion on a bipolar rating scale (Figure 3). The bipolar scale was chosen to make use of the two contrasting terms helping to define each other (Bortz \& Döring, 2006) so all non-native-English speaking participants were able to understand. Since there was no significant probability of a central tendency, the participants were asked to score on a five-point scale based on school grade system as this turned out as the most familiar form of doing the rating. The questionnaire contained 17 questions concerning process, content, moderation and learning success of the workshop. The questionnaires closed with four open questions concerning suggestions for improvement and further content. The number of the valid responses was 47 while the total amount of all participants in the workshops was around 1/3 higher. The data of the open questions was analysed with reference to qualitative content analyses (Mayring, 2010) by using techniques of interpreting, structuring and categorising. The results were processed for each workshop to uncover country specific aspects of the evaluation. The results were presented and discussed during one of the transnational meetings of the project. 


\begin{tabular}{|r|rrrrrr|l|}
\hline \multicolumn{1}{|c|}{ The atmosphere was } \\
\hline $\begin{array}{r}\text { very } \\
\text { comfortable }\end{array}$ & $\square$ & $\square$ & $\square$ & $\square$ & $\square$ & very tense \\
\hline & $\mathrm{I}$ & 2 & 3 & 4 & 5 & \\
\hline
\end{tabular}

Figure 3. Item of train-the-trainer workshop evaluation (own source)

\section{Evalution results (summary)}

First of all, it is important to note that the results are derived from the specific project context and are thus not transferable in a general manner onto other EU situations, nor do they possess much empirical scope. Nevertheless, important lessons for educational models in the European context in respect to sustainability in business and for the further improvement of the developed QCC can be found. The overall evaluation of the quantitative data is provided in Figure 4 (Finland $n=6$, Austria $n=9$, Hungary $n=10$, Slovakia $n=9$, Spain $n=13$; average data of each country used).

\section{Prior knowledge as a limiting factor}

First, it can be stated that a wide range of knowledge about trainings in general and about sustainability/sustainable management in particular characterises the prior knowledge of trainers in further vocational education. Pre-training in issues of sustainability, sustainable business and sustainable production could be beneficial and would in any case homogenise participants.

\section{Didactic approach was suitable}

The participants gave positive feedback on the didactic approach of the seminars. The mixture of informative parts and active work was rated as comfortable. Especially creative and reflexive methods were rated as useful. Despite the critique regarding the duration of the seminar (too long, to short), many participants would have liked more (but time consuming) active parts and concrete exercises. It seems appropriate to evaluate the approach for blended learning also in such a format as the QCC and to assign participants more selfresponsibility for seminar related tasks. 


\section{Self-assessment and special modules were attracting}

The self-assessment (B2) was rated as very useful. To draw more attention to it, a short preview could be made at the beginning of the first day of the workshop and time for practicing could be extended (even if it is already assigned a long time slot). Furthermore, the special modules component could be expanded, since the majority of the participants wished deeper examinations of these.

$\square$ Spain $\square$ Slovakia $\square$ Hungary $\square$ Austria $\square$ Finland

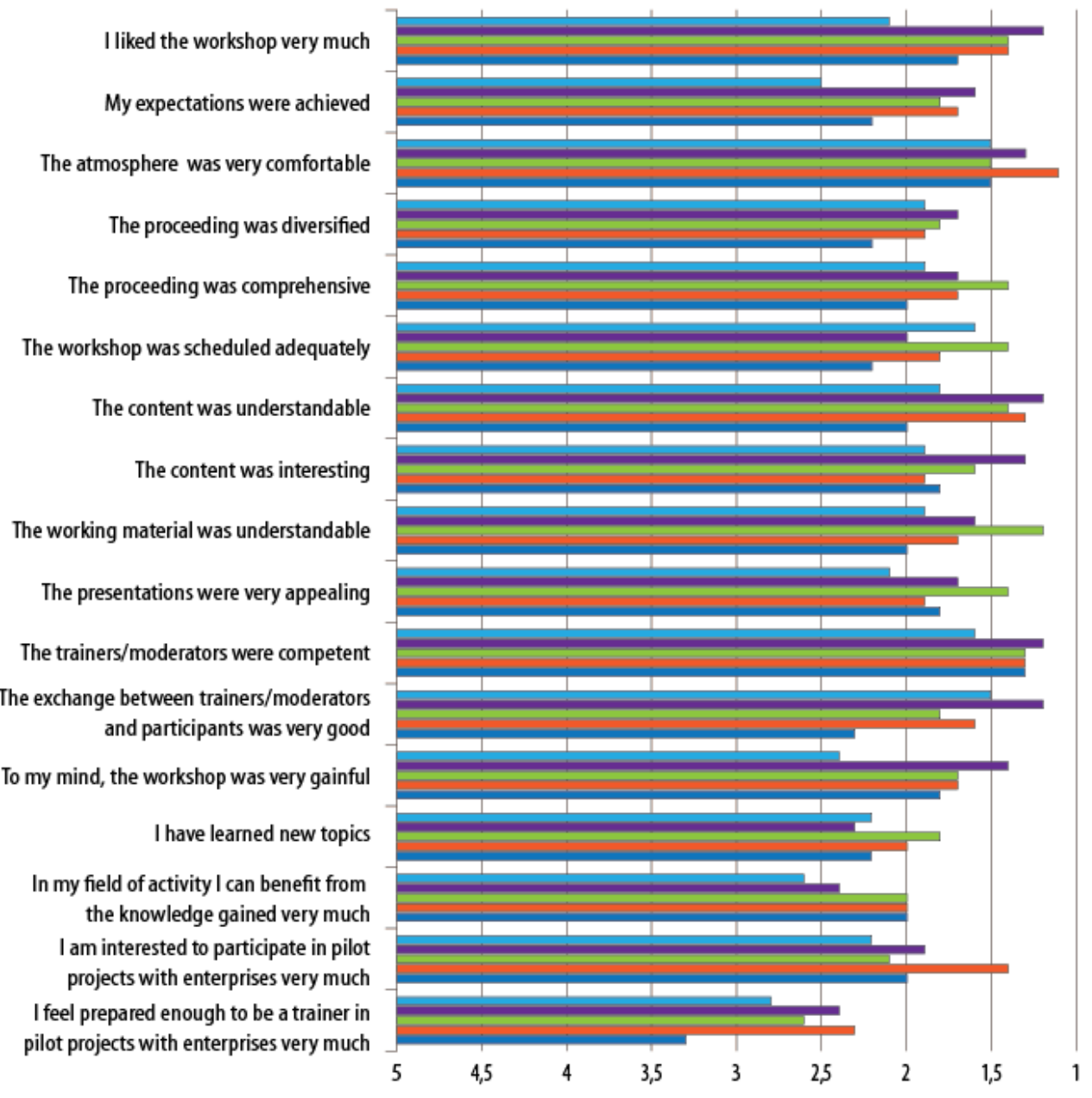

Based on school grading system ( 1 = best mark, highest agreement; $5=$ worst mark, lowest agreement)

Figure 4. Evaluation results of train-the-trainer workshops, quantitative data (own source) 


\section{Feeling able to act autonomously}

The majority of the participants felt able in parts to act as a trainer in enterprises when making concrete use of the QCC after the seminar. The reservations expressed from the participants can be set in correlation mainly to the short duration of the workshop and the high fluctuation of participants' attendance during workshop days and between the two days of the workshop. In addition to that, the different levels of the participants' language proficiency seemed a hindrance.

Those participants who expressed their interest in pilot-testing with enterprises using the QCC have to be supported and guided by transnational project partners at first - the workshop has built a good stock of knowledge concerning the approach, content, methods and structure of the QCC, but has to be completed in a team effort of project partners and external trainers.

\section{Discussion}

\section{Starting points for a European qualification and consulting concept}

The work on EuroCrafts 21 has shown that the innovation transfer of the German approach was successful and that the QCC and the train-the-trainer design, as an instrument, is useful also for European contexts. Taking into account the lessons learned, the obvious question is what adoptions and what kind of further development is necessary to build up a fully developed EQCC.

The following recommendations have to be understood with regard to the background of the project and the specific experiences the project partners made when working on the targets of EuroCrafts 21. The recommendations offer valuable perspectives and suggestions but do not claim to be universally valid.

\section{Which content should be central to the EQCC?}

The design of the special modules of the QCC, which was developed in the project EuroCrafts 21, resulted from the identified country specific qualification needs. Therefore, the special modules reflect these specific needs. When increasing the number of modules, the challenge whether new additional topics are to be assigned to an existing module or whether totally new modules are to be added will arise. Topics such as resource efficiency in production and along the value chain are relevant future topics (Rohn, Pastewski, \& Lettenmeier, 2010; Schmitt, Klinke, \& Rohn, 2011).

The identification of these basic topics should result from a European meta-analysis and should be pre-specified. This would ensure that the crucial European needs with reference to European-wide qualification contents for SMEs in the European handicraft sector are taken into account. In this context, political decision-makers should also be involved. 
Which target groups should the expansion to the EQCC be designed for and which adaptions to the format would be necessary?

The target group of the EuroCrafts 21 product consists of educational staff at vocational education and training institutes, factory owners and business executives as well as consultants and multipliers of further education.

It should be questioned whether further target groups on the European level could make use of an EQCC and which medial adjustments to the present concept would be necessary in this context (for instance, EQCC as a blended learning concept).

\section{Which operational level of the (national) educational systems is suitable?}

In the framework of the project EuroCrafts 21 so far mainly the sector of non-formal (vocational) further education was addressed. The question arises whether expansion might serve the integration of target groups on additional levels of the educational systems. In Finland, for instance, the train-the-trainer workshop raised great interest not only among the 'main' target group of the trainers but also among students. An analysis of the curricula of relevant fields of study might reveal the extent to which sustainability and sustainable business etc. are already established and the possible 'points of entry' to integrate aspects of sustainability. This would create a remarkable value added for education in the tertiary sector in Germany and on comparative levels in the educational systems of other European countries. Consequently, an adjustment of the curricula on different levels of the European educational systems should also include a qualification of teaching staff. Trainees of crafts enterprises could be a further target group for the EQCC in formal vocational training and further education.

\section{How can the QCC be linked and aligned to European educational policy?}

With regard to the subject matter of EuroCrafts 21, the efforts of European educational policy in the development of skills and European comparability are central and provide 'guidelines' for the development of an EQCC.

Qualification and the development of competencies in the corporate context serve the aim of enabling employee involvement in innovation processes using their expert (technical) know-how. Furthermore, knowledge and skills that go beyond the expert qualification are very important.

With regard to the existing product of EuroCrafts 21 the 'competence approach' is implicitly represented in the didactic design of the tested and further developed QCC but should be made more explicit in the advancement process. With reference to European educational policy and the attempts to achieve comparability of competencies on the European level, educational objectives of the respective modules and/or separate learning material should be made explicit in the framework of monitoring educational goals. This would also strengthen the concept's output-orientation. Such explicit framing is the first prerequisite 
for the achievement of European comparability with respect to the learners' competencies, skills and qualifications. It, furthermore, serves the alignment with the European Qualification Framework (EQF).

\section{Conclusion}

Previously, pointers from the evaluation of the train-the-trainer design were highlighted and first fields for further development of the QCC were devised. In conclusion, EuroCrafts 21 can be described as a successful innovation transfer project. The approach and the didactical processing has stood the test and allowed adaption by partner countries. The QCC as a product follows the European recommendations of the German Federal Institute for Vocational Education and Training (Winzier 2009). On the didactic level, it furthermore makes reference to widely accepted concepts of education for sustainable development (Programm Tranfer 21, 2007).

The development of an EQCC in the sense outlined and discussed above is a logical next step in order to significantly add value to the European educational effort in perusal of more sustainable business practices.

\section{References:}

Anlauft, W. (2007). Unternehmenskultur innovationsförderlich gestalten - ein Weg zu wirtschaftlichem Erfolg und guter Arbeit [An innovation-friendly corporate culture - a pathway to economic success and good work]. In D. Streich \& D. Wahl (Eds.), Innovationsfähigkeit in einer modernen Arbeitswelt: Personalentwicklung - Organisationsentwicklung - Kompetenzentwicklung [An innovative ability in a modern world of employment: Human resource development - organisational development - development of competencies] (pp. 387-399). Frankfurt: Campus Verlag.

Arnold, R. (1999). Konstruktivistische Ermöglichungsdidaktik [Constructivistically enabling didactics]. In R. Arnold, W. Gieseke \& E. Nuissl von Rein (Eds.), Erwachsenenpädagogik - zur Konstitution eines Faches [Adult education - constitution of a subject] (pp.18-28). Hohengehren: Schneider Verlag.

Bortz, J., \& Döring, N. (2006). Forschungsmethoden und Evaluation für Human- und Sozialwissenschaftler [Research methods and evaluation for human and social scientists]. Heidelberg: Springer.

Bund-Länder-Kommission (BLK) für Bildungsplanung und Forschungsförderung [BundLänder Commission for Educational Planning and Research Promotion]. (1998). Bildung für eine nachhaltige Entwicklung - Orientierungsrahmen [Education for sustainable development - guide]. (BLK publication No. 69). Bonn: Author.

European Commission. (2007). Opportunity and responsibility. How to help more small businesses to integrate social and environmental isues into what they do. Retrieved from http://ec.europa.eu/enterprise/policies/sustainable-business/files/csr/documents/re e_report_en.pdf 
Hartmann, D. M., Brentel, H., \& Rohn, H. (2006). Lern- und Innovationsfähigkeit von Unternehmen und Organisationen. Kriterien und Indikatoren [Learning ability and innovation ability of enterprises and organisations. Criteria and indicators]. (Wuppertal Paper No.156). Wuppertal: Wuppertal Institut für Klima, Umwelt, Energie.

Henning, K., Oertel, I., \& Isenhardt, I. (Eds.). (2003). Wissen - Innovation - Netzwerke. Wege zur Zukunftsfähigkeit [Knowledge - Innovation - Networks. Paths to future viability]. Berlin: Springer.

Holzkamp, K. (1996). Wider den Lehr-Lern-Kurzschluß. Interview zum Thema Lernen [Against the teaching-learning-blackout. Interview on the subject learning]. In R. Arnold (Ed.), Lebendiges Lernen [Lively learning] (pp. 21-30). Hohengehren: Schneider Verlag.

Leinonen, R., \& Ryynänen, S. (2010). Euro Crafts 21 - developing competencies for sustainable management in European handicrafts. Lifelong Learning in Europe, XV(04), 196.

Mandl, I., \& Dorr, A. (2007). SCR and Competitiveness - European SMEs' good practice. Retrieved from http://www.ifm-bonn.org/assets/documents/CSR-Europa.pdf

Manstein, C., \& Rohn, H. (Director/Producer). (2010). EU project “Euro Crafts 21". Qualification and Consulting Concept [CD-ROM]. Vienna: Authors.

Mayring, P. (2010). Qualitative Inhaltsanalyse. Grundlagen und Techniken [Qualitative content analysis. Basics and techniques]. Weinheim: Beltz.

Pätzold, G., \& Wortmann, E. (2006). Didaktische Handlungsmöglichkeiten zur Ausbildung von Schlüsselqualifikationen [Didactic possibilities for promotion of key competencies]. In R. Arnold \& H.-J. Müller (Eds.), Kompetenzentwicklung durch Schlüsselqualifikations-Förderung [Competence development through promotion of key qualifications] (pp. 155-173). Hohengehren: Schneider Verlag.

Programm Transfer 21. (2007). Multiplikatorenmodule [Modules for multipliers]. Retrieved from http:/www.institutfutur.de/transfer-21/daten/multiplikatoren/modul2.pdf

Rohn, H., Pastewski, N., \& Lettenmeier, M. (2010). Resource efficiency of selected technologies, products and strategies: executive summary. Summary of task 1 within the framework of the "Material efficiency and resource conservation" (MaRess) projects (Resource efficiency paper No. 1.7). Wuppertal: Wuppertal Institut für Klima, Umwelt, Energie.

Schmitt, M., Klinke, S., \& Rohn, H. (2011). Was zeichnet ressourceneffiziente, innovative $K M U$ aus? [What characterises resource efficient, innovative SMEs?] (RessourcenKultur Paper No. 4). Wuppertal: Wuppertal Institut für Klima, Umwelt, Energie.

Schüßler, I. (2003). Ermöglichungsdidaktik - eine didaktische Theorie? [Enabling-didactics - a didactic theory?]. In R. Arnold \& I. Schüßler (Eds.), Ermöglichungsdidaktik. Erwachsenenpädagogische Grundlagen und Erfahrungen [Didactic of enabling. Basics and experiences of adult education] (pp. 76-97). Hohengehren: Schneider Verlag.

Siebert, H. (2006). Theorien für die Praxis [Theories for the practice]. Bielefeld: Bertelsmann.

Siebert, H. (2005). Pädagogischer Konstruktivismus. Lernzentrierte Pädagogik in Schule und Erwachsenenbildung [Pedagogical constructivism. Learning-focused pedagogy in school and adult education]. Weinheim: Beltz. 
Stadelmann, C. (2004). Messung und Beurteilung des Kulturwandels bei PostMail [Evaluation and assessment of cultural change at PostMail]. (Lizentiatsarbeit). Retrieved from http://www.iop.unibe.ch/lehre/lizentiatsarbeiten/LizStadelmann-Christoph.pdf

Stengel, O., Liedtke, C., Baedeker, C., \& Welfens, M. J. (2008). Theorie und Praxis eines Bildungskonzepts für eine nachhaltige Entwicklung. Umweltpsychologie [Ecological psychology], 12(2), 29-42.

UEAPME - the European Association of Crafts, Small and Medium-Sized Enterprises. (2010). Crafts and SME priorities fort the new R\&D and innovation Strategy. Retrieved from http://www.ueapme.com/IMG/pdf/100713_SME_Innovation_Competitiv eness-Council_final.pdf

Welfens, M., Liedtke, C., \& Schaefer, I. (2008). Encouraging sustainability: Educational program for civil society. Journal Internationale Schulbuchforschung, 30(2), 659-674.

Westdeutscher Handwerkskammertag (WHKT) [West German Chambers of Crafts and Skilled Trades' Council] (Director/Producer). (2007). Nachhaltiges Wirtschaften in Handwerksbetrieben [Operating sustainable in craft enterprises] [CD-ROM]. Düsseldorf: Author.

Winzier, D. (2009). Berufliche Bildung für eine nachhaltige Entwicklung. Meilensteine, Vereinbarungen und Ergebnisse [Vocational education for sustainable development. Milestones, agreements and results]. In Nationale Agentur Bildung für Europa beim Bundesinstitut für Berufsbildung (BIBB). Europäische Kompetenzentwicklung zum nachhaltigen Wirtschaften in der Ernährungsbranche [Education for Europe - National Agency at Federal Institute for Vocational Education and Training (BIBB). European competence development for beeing able to operate sustainable in the sector of food and nutrition] (pp. 28-32). Bonn: Ministerium für Schule und Weiterbildung des Landes Nordrhein-Westfalen.

\section{Correspondence:}

Anna Bliesner, PhD, Wuppertal Institute for Climate, Environment, Energy. Doeppersberg 19, 42103, Wuppertal, Germany. Tel: +49-(0)202/2492-152. Email: annabliesner@wupperi nst.org 